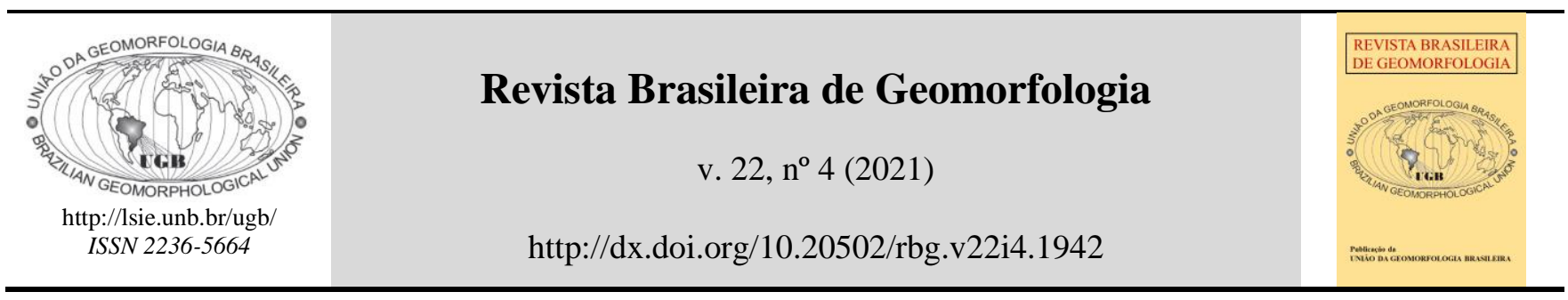

Artigo de Pesquisa

\title{
Modelagem da erosão hídrica potencial no Parque Nacional Serra da Capivara, Nordeste do Brasil
}

\author{
Modeling the potential of hydrological erosion in the Serra da Capivara \\ National Park, Northeast Brazil
}

\section{Renê Jota Arruda de Macêdo ${ }^{1}$, Janaina Carla dos Santos ${ }^{2}$ e Leandro Surya ${ }^{3}$}

1 Universidade Federal do Vale do São Francisco, Colegiado de Ciências da Natureza, São Raimundo Nonato, PI, Brasil. rene.macedo@univasf.edu.br.

ORCID: https://orcid.org/0000-0001-5943-6317

2 Universidade Federal do Vale do São Francisco, Colegiado de Arqueologia e Preservação Patrimonial, São Raimundo Nonato, PI, Brasil. janaina.santos@univasf.edu.br

ORCID: https://orcid.org/0000-0001-5341-6219

3 Universidade Federal do Vale do São Francisco, Programa de Pós-graduação em Arqueologia, São Raimundo Nonato, PI, Brasil. leandro.surya@univasf.edu.br

ORCID: https://orcid.org/0000-0001-9342-1071

Recebido: 20/05/2020; Aceito: 08/07/2021; Publicado: 01/10/2021

Resumo: Erosão consiste no conjunto de processos naturais que removem e transportam os materiais produto do intemperismo. Um dos meios mais conhecidos de estimar o potencial erosivo se dá a partir de medidas que envolvem a relação declividade e seu comprimento de rampa, pelos quais extrai-se o potencial de perda de solo. Por encontrar-se inserido na região semiárida, naturalmente sensível aos processos erosivos, e pelo valor cultural (abrigo de artefatos arqueológicos) e ambiental (fauna e flora da Caatinga), o presente trabalho realizou o mapeamento de áreas vulneráveis à erosão a partir do fator topográfico LS extraído da Equação Universal de Perda de Solos (EUPS) para a área do Parque Nacional Serra da Capivara (PNSC), sudeste do Piauí. A modelagem do fator LS deu-se através de modelos digitais de elevação dos quais computou-se os mapas de gradiente de terreno e fluxo acumulado. Os modelos gerados nos mapas mostram que o reverso da cuesta é responsável pela maior captação do escoamento superficial para área N-NW do PNSC, sendo no total quatro áreas de drenagens. O fator adimensional LS apresentou valor médio de 7,1 e coeficiente de variação de aproximadamente $17 \%$, indicando alta heterogeneidade topográfica. Os maiores valores do fator LS concentram-se em áreas de relevos dissecados de exumação de patamares estruturais e escarpas erosivas dos cânions, que são regiões que abrigam os sítios arqueológicos. Este mapeamento primário possui relevante importância, pois subsidia as tomadas de decisão para fins de preservação do patrimônio arqueológico da região e do conhecimento dos processos de evolução do relevo sedimentar da borda da Bacia do Parnaíba.

Palavras-chave: erosão; geomorfologia; semiárido

\begin{abstract}
Erosion involves a set of natural processes that remove and transport weathered materials. One of the best known methods for estimating erosional potential is by evaluating the relationship between terrain slopes and their lengths, from which the soil loss potential can be derived. We undertook the mapping of vulnerable areas in the Serra da Capivara National Park (SCNP) based on the topographic LS-factor derived from the Universal Soil Loss Equation (ULSE). The Park has high cultural (records of archeological artifacts) and environmental value (the fauna and flora of the Caatinga biome), and is located in the semiarid region of southeastern Piauí State, Brazil - a region that is naturally sensitive to erosional processes. The modeling of the LS-factor was performed using digital terrain models that could generate slope and flow accumulation maps.
\end{abstract}


The models produced on the maps show that the reverse slopes were responsible for the major surface water runoff towards to N-NW area of the SCNP, with a total of four major drainage zones. The LS-factor presented a dimensionless average of 7.1, with a coefficient of variation of approximately $17 \%$ - indicating a highly heterogeneous topography. The major values of the LS-factor are concentrated in areas with dissected relief with exhumed structural steps and erosional canyon scarps that shelter archaeological sites. This primary mapping is of great importance for subsidizing public and private investments in preserving the regional archaeological heritage, as well as our knowledge of landscape evolution along the edge of the Parnaíba Sedimentary Basin.

Keywords: erosion; geomorphology; semiarid

\section{Introdução}

Erosão consiste num conjunto de processos naturais que removem os materiais produto do intemperismo, transporta-os e modela a paisagem (FLORENZANO et al., 2008; SUGUIO, 2003). Os processos erosivos são gerados por forçantes geomórficas resultantes da combinação entre as forças da gravidade, efeitos climáticos e da ação de animais e plantas (HUGGET, 2007). A interação e intensidade entre as forçantes são responsáveis pelo mecanismo de movimento mecânico das partículas sedimentares. Estes materiais são retirados de regiões mais altas majoritariamente por atuação do escoamento superficial e fluxos gravitacionais, transportados e depositados em regiões de menores altitudes. Os movimentos de massa ou gravitacionais, como o rastejo de solo, deslizamentos de terra e escorregamentos, geralmente realizam o papel inicial de movimentar os sedimentos de encostas íngremes, em curtas distâncias, para áreas em que outros processos de transporte continuem atuando (BOGGS, 2006). Tais fenômenos constituem parte dos processos exógenos do sistema geomórfico na formação do relevo que são controlados pelo clima, sendo a erosão responsável pela modelagem e destruição das feições construídas pelas forças geológicas internas (HUGGET, 2007).

As formas de relevo são controladas por duas condicionantes morfogênicas principais: o tipo de substrato rochoso (geologia do terreno) e o clima atuante sobre este (GUERRA \& CUNHA, 2007). No entanto, ressaltam os autores, que estas condicionantes nem sempre são capazes de explicar determinadas formas de relevo e, portanto, devem-se considerar os processos que geram as formas das paisagens, como critérios de classificação das feições geomorfológicas. Logo, o tipo de agente erosivo observado (ar, vento, chuva e etc.) é um dos principais recursos utilizados na descrição dos processos de modelagem e evolução do relevo. Nesse contexto, a vegetação possui um papel importante no controle da intensidade dos efeitos da ação mecânica do escoamento superficial sobre o solo. Sua presença dissipa parte da energia cinética das gotas da chuva minimizando o impacto destas sobre o solo e a tensão de cisalhamento em sua superfície limitando os efeitos da erosão por escoamento superficial (WILLGOOSE, 2018). Bezerra \& Cantalice (2006) realizaram experimentos da ação erosiva da chuva em diferentes condições de cobertura vegetal em áreas de cultivo de cana-de-açúcar e demonstraram um menor escoamento superficial e taxa de infiltração maior quando há aumento na densidade da cobertura do solo pela vegetação.

Em regiões semiáridas e áridas, os processos erosivos são associados a regimes pluviométricos concentrados em determinado período do ano e pela suscetibilidade à erosão de determinados tipos de solo, especialmente os rasos (SILVA et al., 2009; RAPP, 1986). A esparsa cobertura da vegetação e o desmatamento contribuem para uma maior intensidade dos efeitos erosivos. Neste caso, a erosão hídrica, causada pelas chuvas depende fundamentalmente da infiltração da água, da topografia, do tipo de solo e da densidade da cobertura vegetal existente (WISCHMEIER \& SMITH, 1978).

No contexto do semiárido brasileiro (SAB), cuja área aproximada de 1,5 milhão de $\mathrm{km}^{2}$ abrange 9 estados brasileiros e que possui uma grande variabilidade espacial, temporal e quantitativa das chuvas, a erosão hídrica é um problema que conduz ao agravamento da desertificação de áreas que levam à perda da camada superficial rica em matéria orgânica (SANTOS et al., 2010; NETO et al., 2017). O índice de aridez médio anual (Iamed) para maior parte da região varia de 30 a 60, sendo que a região central do SAB, nos limites entre os estados de Pernambuco e Piauí, os índices são acima de 60, enquanto que no extremo norte do Maranhão e Sul da Bahia estão abaixo dos 30 (SANTOS et al., 2010), caracterizando a irregular distribuição e escassa pluviosidade. Os períodos chuvosos são concentrados e apresentam médias de dias de chuva que vão de 62 a 109 dias por ano (SILVA et al., 2011). A vegetação é caracterizada pela Caatinga esparsa com porte arbustivo e arbóreo de folhagem decídua (SILVA et al., 
2010). Estima-se que 54,7\% dessa cobertura vegetal seja remanescente, sendo a expansão agropecuária e das malhas urbanas as principais causas de sua retração (CASTELLETTI et al., 2003).

O conhecimento da vulnerabilidade à erosão de uma determinada região permite identificar e melhor compreender as morfoesculturas, gerando subsídios à gestão territorial, além de viabilizar a simulação de cenários futuros frente aos processos erosivos (SANTOS et al., 2007). Por meio de Sistemas de Informação Geográfica (SIG) é possível realizar simulações computacionais de escoamento de fluídos sobre modelos digitais de elevação (MDE) (MITASOVA et al., 1996) a um baixo custo e num curto intervalo de tempo (HENGL \& REUTER, 2009). Deste modo, mapas de vulnerabilidade à erosão hídrica tornam-se importantes produtos resultantes dessas análises para estimar os processos de erosão/deposição e orientar tomadas de decisões que visem um melhor gerenciamento do espaço estudado.

O Parque Nacional Serra da Capivara (PNSC) é uma Unidade de Conservação (UC) inserida no semiárido nordestino. Constitui uma pequena fração da Caatinga preservada que ainda conserva os aspectos biológicos (fauna e flora) e físicos (geologia, geomorfologia e solos) sem alterações antrópicas marcantes. Além disso, é uma importante fonte de informação arqueológica com diversos registros rupestres e artefatos produzidos pelos povos pré-históricos que ocuparam a região. Este trabalho teve como objetivo realizar modelagens de erosão hídrica a partir da topografia do PNSC a fim de gerar um mapa de áreas potenciais de erosão através de MDE.

\section{Modelagem da Erosão}

A estimativa de erosão hídrica de solos em uma determinada área da superfície terrestre implica numa tarefa de difícil execução, dada à complexa forma, extensão do relevo e o elevado custo para abranger a área de estudo. No entanto, tais limitações podem ser superadas através da modelagem computacional utilizando dados topográficos de sensores espaciais disponíveis gratuitamente e algoritmos computacionais que simulam processos de escoamento, erosão, transporte, dentre outros processos, sobre e sob a malha digital do terreno. Alguns destes algoritmos possuem modelos embutidos em sistemas de manipulação de dados geoespaciais, como programas SIG que armazenam as variáveis espaciais em diferentes camadas e efetuam as operações matemáticas para o cálculo das estimativas (BORGES, 2009). Um dos modelos mais simples e amplamente utilizado na predição de áreas vulneráveis à erosão se dá pela Equação Universal de Perda de Solo (EUPS), formulada por Wischmeier \& Smith (1978). Consiste em um modelo de erosão hídrica laminar que busca determinar a perda de solo de forma quantitativa (GURGEL et al., 2011). A elaboração da EUPS (Eq. 1) foi originalmente criada para aplicações em terrenos planos cujas declividades e seus comprimentos foram obtidas empiricamente (MITASOVA et al., 2004).

$$
A=R K L S C P
$$

Onde A resulta do produto que expressa a perda de solo por unidade de área em toneladas por acre ao ano ( $\mathrm{t} / \mathrm{A} / \mathrm{a})$; R é o índice pluviométrico e fator de escoamento (runoff) - índice de erosividade da chuva (rainfall erosion index); K consiste no fator da erosividade do solo; L é o fator que considera o comprimento de um declive; $\mathrm{S}$ é o fator de esbeltez do declive; C é o fator de uso e manejo de uma área agricultável; e P é fator de suporte à prática - razão da perda de solo com as práticas de culturas conservacionistas.

\subsection{Fator Topográfico LS}

A influência do terreno sobre os processos erosivos é representada pelo fator topográfico adimensional LS, que mede o impacto do comprimento de uma rampa na erosão do solo sob condições de alta inclinação (CAPOLONGO et al., 2008). O fator L é caracterizado como a distância do ponto de origem do caimento da água até o ponto em que ela decresce propiciando a sedimentação em rupturas de uma vertente junto a vales (WISCHMEIER \& SMITH,1978). O fator S, da declividade do terreno, mede o gradiente de inclinação da rampa. Os valores do fator LS podem ser obtidos a partir da equação empírica (Eq. 2) de Wischmeier e Smith (1978):

$$
L S=(\lambda / 22.13) m\left(65.41 \operatorname{sen}^{2} \theta+4.56 \operatorname{sen} \theta+0.065\right)
$$

Onde $\lambda$ é o comprimento da projeção horizontal da declividade medida em metros, m é a constante dependente do valor da declividade e $\theta$ é o ângulo da declividade. Ressalva-se que a EUPS considera apenas a 
erosão ao longo de linhas de fluxo sem a influência da divergência e/ou convergência destas, sendo aplicada apenas em áreas que passam por processos erosivos. Posteriormente a formulação foi adaptada para aplicação em terrenos complexos (Eq. 3), através da reaplicação do comprimento de rampa utilizando a área de contribuição (DESMET \& GOVERS, 1996):

$$
L S=(m+1)(U / 22.1) m(\operatorname{sen} \beta / 0.09) n
$$

Onde $U$ é a área de contribuição por unidade de largura (medida do fluxo de água), em $\mathrm{m}^{2} / \mathrm{m} ; \beta$ é o ângulo da declividade em graus, 22.1 metros é a largura e $0.09=9 \%=5.15^{\circ}$ é o valor padrão de declividade da EUPS; os valores de $m=0.4$ e $n=1.3$ são constantes empíricas.

$\mathrm{Na}$ nova abordagem, que considera a área de contribuição de um terreno, o fator LS deixa de ser unidimensional e passa a ser bidimensional quando aplicado com SIG em largas áreas. Tal fato decorre da capacidade de identificar regiões em convergência ou divergência de fluxos que pode aumentar ou diminuir a capacidade de transporte de sedimentos (ZHANG et al., 2013).

Além da simplicidade em aplicar a EUPS na identificação de áreas vulneráveis à erosão, outras vantagens podem ser observadas como dados prontamente disponíveis através de imagens de sensor e compatibilidade com SIG (SHI et al., 2004).

\section{Caracterização da Área de Estudo}

O PNSC foi criado em 1979 como unidade de conservação ambiental por apresentar grande potencial turístico e científico, advindo das paisagens de grande beleza cênica no bioma Caatinga e abrigar vários sítios arqueológicos, muitos com pinturas rupestres presentes nos afloramentos rochosos da região descobertas em 1970 (PESSIS \& GUIDON, 2007). Cerca de 900 sítios arqueológicos foram mapeados até o momento, contendo: pinturas, gravuras, vestígios líticos, vestígios cerâmicos, fogueiras, ossos de habitantes pré-históricos, além de fósseis de fauna pleistocênica que ocuparam a região. Além desses valores artísticos, culturais e científicos, o parque apresenta uma geomorfologia de beleza marcante resultante de processos geológicos e geomórficos ao longo do desenvolvimento da bacia sedimentar do Parnaíba. O relevo cuestiforme da região é marcado por longos e aprofundados vales, do tipo cânion, entalhados ao longo de milhares de anos, espacialmente dispostos nas regiões periféricas limítrofes do PNSC, que correspondem a borda da bacia Sedimentar do Parnaíba esculpida na forma de escarpa. Nessa área os cânions são comumente conhecidos como boqueirões e recortam as formações geológicas desenvolvendo extensos paredões íngremes.

Durante o inverno, a precipitação intensa e rápida, favorece o aprofundamento dos vales pela formação de fluxos de escoamento efêmeros. As escarpas erosivas adjacentes passam por movimentos de massa do tipo queda de blocos. Esses processos podem estar associados à erosão pluvial nos sistemas de diáclases de orientação preferencial NW-SE, conforme caracterizado por Barbosa \& Furrier (2012). Na base, ao longo de quase todos os paredões rochosos, encontram-se cavidades formadas por erosão diferencial. Essas feições geomorfológicas serviam de abrigo para as populações pré-históricas, onde encontra-se a maioria das pinturas rupestres da região do parque que constituem os registros culturais desses povos (PESSIS \& GUIDON, 2007).

O PNSC possui uma área de 130.000 ha e está localizado no sudeste do estado do Piauí (Figura 1), compreendendo parte dos municípios de João Costa, Brejo do Piauí, Coronel José Dias e São Raimundo Nonato, este último, considerado a sede do parque. A área de estudo está situada no semiárido nordestino onde o clima é do tipo Bsh, segundo a classificação de Köppen. 


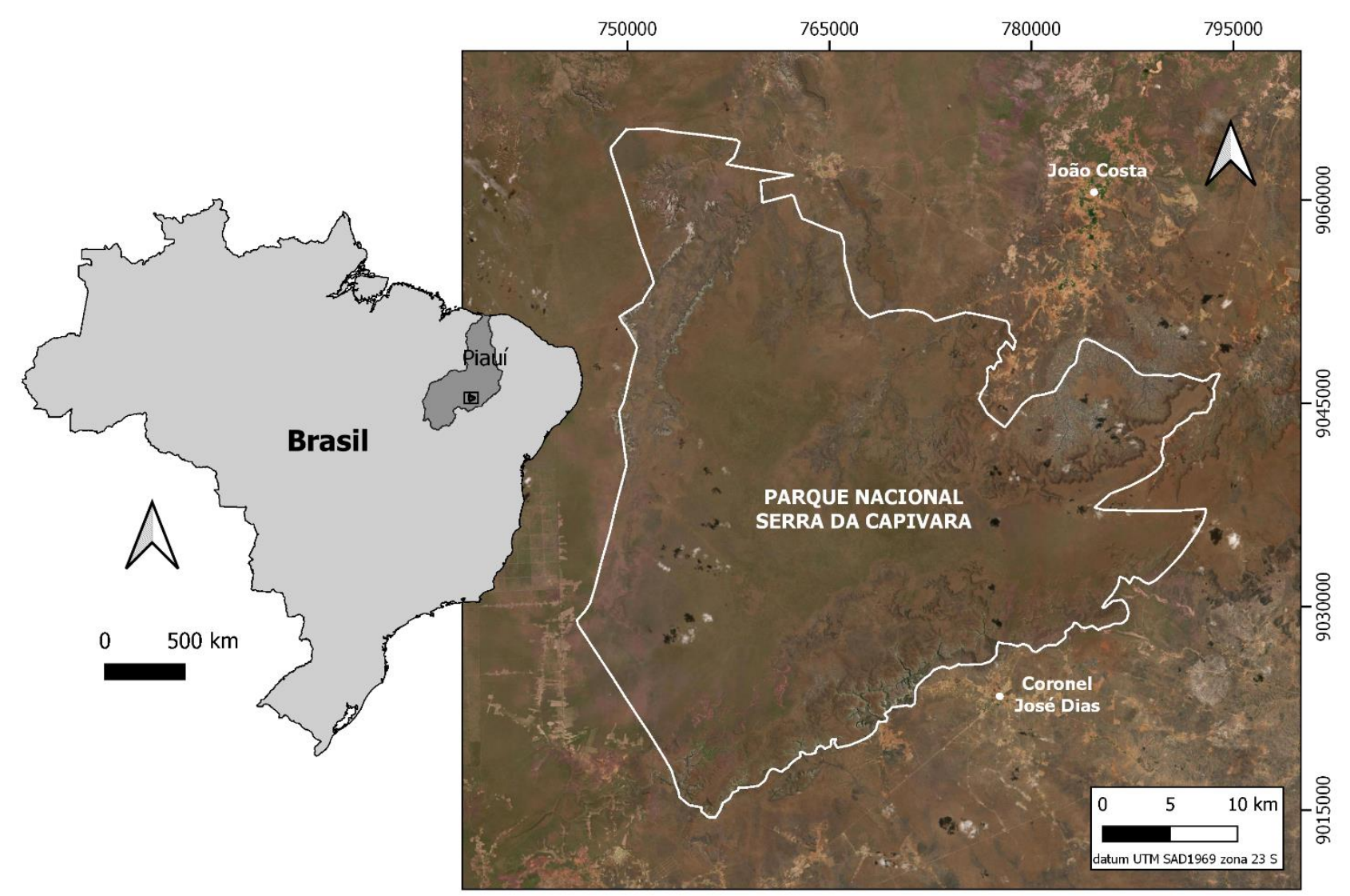

Figura 1. Localização e limite da área de estudo. Fonte: Esri Satellite World Imagery.

A temperatura média anual é de $28^{\circ} \mathrm{C}$ e a estação chuvosa é caracterizada por um regime irregular que se estende de outubro a abril, apresentando uma precipitação média de $689 \mathrm{~mm} / \mathrm{ano}$ (SANTOS et al., 2012). A estação seca é prolongada por cerca de oito meses, caracterizada pelo baixo índice pluviométrico e média anual de umidade relativa do ar de $20 \%$ (BARROS et al, 2012). A fitofisionomia predominante é do tipo caatinga, com plantas caducifólias, caracterizadas pela perda massiva de suas folhas durante os períodos de estresse hídrico. A vegetação predominante é representada por duas famílias de plantas, cactáceas (espinhosas) e bromeliáceas (suculentas) típicas do semiárido nordestino (FUMDHAM, 1998).

O PNSC está inserido no limite entre dois domínios geológicos, a bacia sedimentar do Parnaíba e a borda do embasamento cristalino Pré-Cambriano, denominada Província Estrutural da Borborema (MABESOONE, 2002). A sinéclise do Parnaíba compreende uma área aproximada de $600.000 \mathrm{~km}^{2}$ alcançando uma espessura máxima de $3.400 \mathrm{~m}$ e abrange os estados do Maranhão, Piauí e parte do Pará, Tocantins e Ceará (JÚNIOR \& NOGUEIRA, 2013). A área do PNSC está contida nos terrenos da bacia sedimentar que foi implantada sobre riftes cambroordovicianos, formada por cinco sequências deposicionais (CPRM, 2003), que são: Sequência Siluriana (Grupo Serra Grande), Sequência Devoniana (Grupo Canindé), Sequência Carbonífero-Triássico (Grupo Balsas), Sequência Jurássica (Grupo Mearim) e Sequência Cretácea (Formações Grajaú, Codó e Itapecuru) (CPRM, 2009).

No que diz respeito ao terreno da Província Estrutural da Borborema, este é definido como um complexo mosaico de regiões dobradas onde ocorreram efetivos e importantes eventos tectônicos, magmáticos e termais de idades neoproterozoicas, assinalados ao Ciclo Brasiliano. Fora dos limites do PNSC, na depressão periférica adjacente ocorre um sistema de dobramentos dentro da Província Borborema com formato irregular, ao longo da área de $28.000 \mathrm{~km}^{2}$. Trata-se da Faixa de Dobramentos Riacho do Pontal, que está localizada na divisa dos Estados do Piauí, Pernambuco e Bahia (BRITO NEVES et al., 2001; ALMEIDA et al.,1977; BRITO NEVES, 1975; CAXITO \& UHLEIN, 2013).

$\mathrm{Na}$ área limite do PNSC afloram duas sequências deposicionais representadas pelos Grupos Serra Grande e Canindé de idades siluriana e devoniana, respectivamente. O Grupo Serra Grande compreende as formações Ipu, Tianguá e Jaicós, sendo a primeira a única que aflora dentro do PNSC. A formação Ipu é caracterizada por arenitos, 
conglomerados e diamictitos depositados em ambiente fluvial anastomosado sob influência periglacial (CAPUTO, 1985). O Grupo Canindé é formado pelas formações Longá, Cabeças, Pimenteiras e Itaim. Afloram no parque as formações: (1) Cabeças, formada por arenitos com intercalações de siltitos e folhelhos; (2) Pimenteiras, constituída de arenitos e siltitos, de coloração avermelhada e ocorrência de nódulos ferruginosos, interpretada como ambiente plataformal marinho, que se sobrepõe em contato direto com a (3) Formação Itaim, formada por arenitos finos e folhelhos acinzentados interpretados de origem de ambientes deltaicos e plataformais (BARROS et al., 2012).

As feições geomorfológicas da área de estudo resultam da combinação entre os eventos geológicos que levaram ao soerguimento de estratos associados à orogenia paleozoica antes da fragmentação do Gondwana (CAPUTO et al., 2005), dos quais derivaram fraturas e processos erosivos sobre as estruturas cuestiformes da borda da Bacia sedimentar do Parnaíba na área de estudo cujos relevos desenvolveram-se pelo forte controle estrutural (BARROS et al., 2011; BARBOSA \& FURRIER, 2012; MUTZENBERG et al., 2015). Notáveis feições escarpadas projetam-se, na borda erosiva resultante do soerguimento dessa área da Bacia do Parnaíba, sobre os maciços constituídos de rochas pré-cambrianas da Formação Barra Bonita onde predominam afloramentos de quartzitos, micaxistos e mármores lenticulares (CAXITO \& UHLEIN, 2013). Na estrutura homoclinal, observam-se as feições clássicas do relevo cuestiforme - o reverso e a cornija areníticos, o front e o depósito de tálus suave que se estende sobre a depressão periférica essencialmente plana, demarcando fisiograficamente o limite no contato entre a bacia sedimentar e o embasamento, com um longo reverso de baixo gradiente com mergulho SE-NW.

O reverso constitui a porção mais plana da área e ocupa a região oeste do PNSC, recoberto de depósitos elúviocoluviais arenosos, formado por chapadas areníticas da Formação Itaim, com superfície tabular de baixo gradiente de mergulho SE-NW pouco dissecada, recortada por vales cataclinais extensos encaixados, de fundo plano, e orientação N-S (SANTOS et al., 2012).

O front apresenta feições ruiniformes bem desenvolvidas geradas pelo seu recuo progressivo por meio de entalhes oriundos da drenagem obsequente (MUTZENBERG et al., 2015), destacando-se relevos residuais como morros testemunhos, isolados ou agrupados em colunas, além de cânions do tipo slot limitados por paredões íngremes e com abrigos na base ondem encontram-se os sítios arqueológicos (BARROS et al., 2011). Os vales entalhados dessa área orientam-se no mesmo sentido de mergulho do reverso (SE-NW), apresentando larga abertura (localmente chamados de boqueirões), de menor extensão em comparação aos demais encontrados no reverso, os quais findam-se com blocos e matacões caídos. Tais vales são responsáveis pela exumação de patamares estruturais planos a suavemente ondulados (SANTOS et al., 2012).

Reconhecem-se três unidades morfoestruturais na região do PNSC, sendo elas (SANTOS et al., 2012): Vale Serra Branca, Reverso da Cuesta e Patamares Estruturais (Figura 2). O Vale da Serra Branca ocorre nas porções norte e oeste, compreendendo uma área depressiva cujo talvegue alcança $400 \mathrm{~m}$ de altitude e o cume das bordas em torno de $520 \mathrm{~m}$. O domínio do Reverso da Cuesta apresenta as maiores altitudes com uma superfície plana e decaimento suave, correspondendo a maior área do PNSC. O domínio dos Patamares Estruturais consiste em patamares com diferentes níveis de altitude, os quais ocorrem em duas subunidades: Patamares Estruturais do Sul (PES) com quatro degraus e Patamares Estruturais do Nordeste (PEN) com apenas dois. 


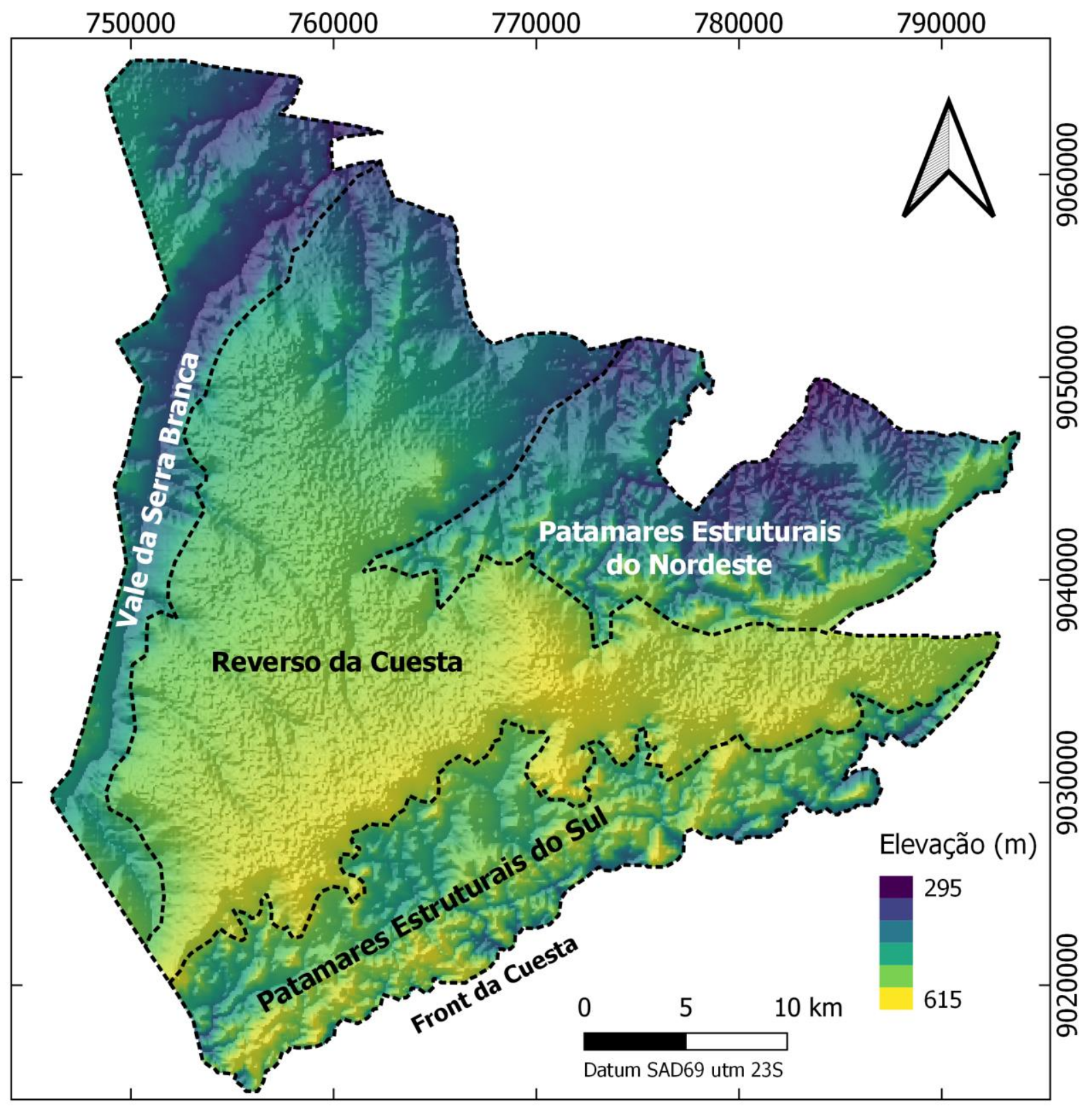

Figura 2. Modelo digital de elevação com relevo sombreado do PNSC e os limites de seus domínios morfoestruturais (Modificado de Santos et al., 2012).

\section{Materiais e Métodos}

A análise de áreas suscetíveis à erosão no PNSC se deu através do uso de imagens SRTM/NASA com resolução espacial de $90 \mathrm{~m}$, adquiridas gratuitamente no site da Embrapa no endereço http://www.relevobr.cnpm.embrapa.br, com referência SC-23-X-B, correspondente à região de estudo. As imagens foram processadas em softwares livres de Sistemas de Informação Geográfica (SIG), Quantum GIS versão 3.0 (QGIS development team, 2019) e Geographic Resources Analysis Support System (Grass). O programa Grass vem incluso no pacote de download e pode ser acessado no ambiente do QGIS.

O recorte da área de estudo foi realizado a partir de um mapa produzido pela Fundação Museu do Homem Americano (FUNDHAM) disponível no site http://www.fumdham.org em formato .jpg. O referido mapa foi georreferenciado no software QGIS aplicando as coordenadas obtidas da imagem base da FUNDHAM. Em seguida os limites do PNSC foram vetorizados gerando um polígono na escala de 1:300.000 referenciada no datum horizontal South American Datum 1969 (SAD69). 
Previamente à análise de terreno realizou-se o ajuste dos valores nulos da imagem SRTM no Grass através do comando r.fillnulls em que células com valores vazios ou faltantes (missing values) foram ajustadas a partir da interpolação dos valores de altitude de células vizinhas. Um novo mapa hipsométrico foi gerado com as cotas altimétricas corrigidas. Para a obtenção do fator adimensional LS foi necessário a construção de modelos de área de contribuição de fluxo e declividade do terreno. O mapa da área de contribuição foi processado utilizando a biblioteca dynatopmodel (METCALFE et al., 2015) disponível para a linguagem computacional R. A extração dessa variável depende da transformação prévia da resolução de cada célula para mesmas dimensões, neste caso, para 90 metros. A função possui embutida as opções de preenchimento de células vazias para que o mapa final tenha as linhas de fluxos acumulados representadas.

\subsection{Determinação dos fatores $L$ e $S$}

A combinação dos fatores $L$ e $S$ geram um valor adimensional e surgem a partir da Equação 2. $O$ fator $L$ vem de $(\lambda / 22.13) \mathrm{m}$, onde $\lambda$ é a projeção horizontal do comprimento da declividade em metros e $\mathrm{m}$ é a constante dependente do valor da declividade. $\mathrm{O}$ fator $\mathrm{S}$, que consiste na esbeltez de uma rampa, resulta da equação (65.41 $\left.\operatorname{sen}^{2} \theta+4.56 \operatorname{sen} \theta+0.065\right)$, onde $\theta$ é o ângulo de inclinação.

Após a obtenção dos fatores L e S separadamente, aplicou-se o cálculo do fator LS utilizando a calculadora raster do Grass através do comando r.mapcalc inserindo a seguinte fórmula (Eq. 4):

$$
\text { fatorls }=(1.4) * \exp (\text { flowacc } * 90 / 22.1,0.4) * \exp (\sin (\text { slope }) / 5.15,1.3)
$$

Onde $(m+1)=$ constante $0.4+1$; e flowacc ${ }^{*} 90$ corresponde a área de fluxo acumulado vezes a resolução do MDE (90 m).

\section{Resultados e Discussões}

Os dados derivados das imagens SRTM 2005 estão disponíveis nas Figuras 3, 4, 5 e 6. As cotas altimétricas variam de $295 \mathrm{~m}$ a $616 \mathrm{~m}$, com altitudes predominantes entre $500 \mathrm{~m}$ e $600 \mathrm{~m}$, correspondendo a aproximadamente 72.000 hectares, cerca de $56 \%$ da área do PNSC, as quais estão presentes em maior parte no domínio morfoestrutural Reverso da Cuesta e no relevo residual dos PES (Figura 3a). Cerca de 77,4 \% da área do PNSC possui gradientes que variam de $0^{\circ}$ a $4^{\circ}$ distribuídos numa área de aproximadamente 97.908 hectares. Os menores gradientes encontram-se nas áreas de topos planos de maiores altitudes da chapada arenítica do reverso da cuesta, cujos declives não ultrapassam os $2^{\circ}$ (Figura $3 b$ ), exceto pelas regiões escarpadas que bordejam os vales encaixados. Observam-se ainda que as formas planas se distribuem na base dos vales, assim como nos patamares estruturais exumados. Maiores gradientes $\left(>4^{\circ}\right)$ ocorrem principalmente associados às formas de relevos residuais nas bordas dos cânions e dos patamares estruturais, assim como no front da cuesta, cujas feições escarpadas ajustam-se a uma imbricada rede de drenagem que resultou numa topografia rugosa, de origem primariamente estrutural. 

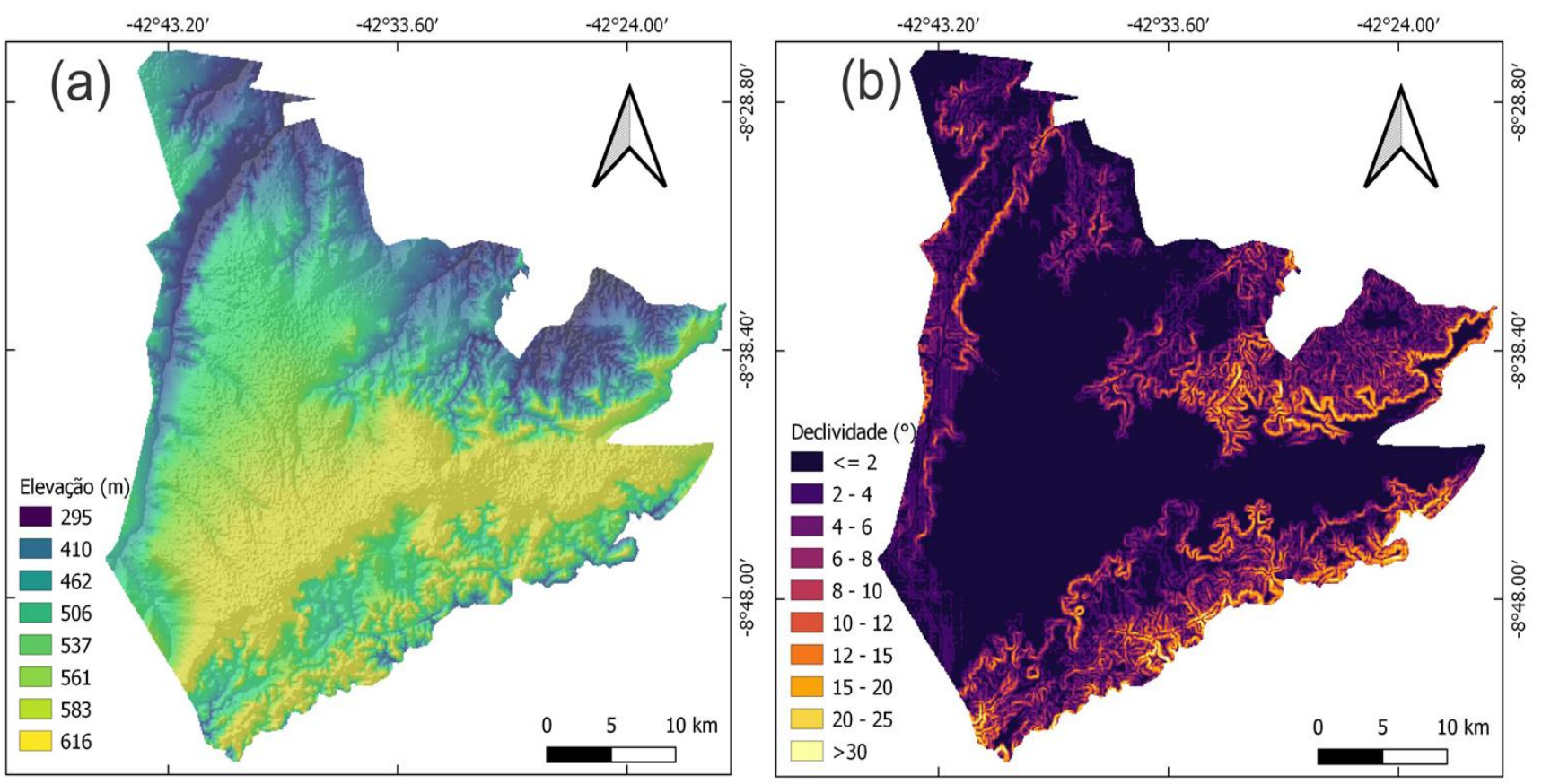

Figura 3. Mapa de elevação (a) e declividade (b) da região do PNSC.

As áreas norte e oeste apresentam as menores altitudes, que variam de $450 \mathrm{~m}$ no reverso da cuesta até aproximadamente 295 m no Vale da Serra Branca e nos cânions entalhados na região dos Patamares Estruturais Nordeste que apresenta relevo escalonado, profundamente dissecado diferencialmente, resultante da instalação de uma rede de drenagem densa sobre os arenitos da Formação Itaím e das rochas pelíticas da Formação Pimenteiras (SANTOS, 2007). No limite sudeste do PNSC, o padrão dissecado do relevo compreende a região dos PES cujo escalonamento ocorre na forma de quatro patamares estruturais com maior extensão superficial do que os que ocorrem na área nordeste do parque, cobertos por depósitos quaternários coluviais e ampla área de relevo ruiniforme, limitados pelo front no limite com o embasamento. Os PES desenvolveram-se pelo forte controle estrutural resultante da projeção da borda da bacia sobre o embasamento cristalino na qual ocorrem sistemas de diáclases de direção predominante NW-SE que permitem a infiltração e intemperização das rochas pelas águas pluviais nas fraturas (SANTOS et al., 2012; BARBOSA \& FURRIER, 2012). Na área dos PEN o relevo residual recobre uma área menor com escalonamento estreito e sem cobertura quaternária (SANTOS, 2007).

A área de contribuição de fluxo está representada pela Figura 4, obtida pelo cálculo de fluxo acumulado computado. O reverso da cuesta apresenta um importante papel na captação dos fluxos hídricos superficiais na modelagem do relevo nas áreas noroeste do Vale da Serra Branca e na porção nordeste. As direções de escoamento seguem orientadas pelo azimute predominante do reverso da cuesta, de modo que os canais principais associados, visíveis pelos talvegues dos vales (Figura 4), possuem segmentos extensos com maiores índices de fluxo acumulado, interceptam cabeceiras de tributários de fluxos dispersos, de menores índices. A área sudeste do PNSC, apresenta um padrão de escoamento mais disperso multidirecional que sua região N-NW. Nessa área que bordeja o front da cuesta a Sul, o escoamento é controlado pelo relevo ruiniforme, que em geral direciona o fluxo para NWSE. As bordas dos vales do front juntamente com as cristas das feições residuais atuam como divisores de água limitando o escoamento para NW.

A partir da interpretação do fluxo acumulado é possível inferir que toda a área do PNSC apresenta a maior densidade potencial de drenagem (DPD) - do inglês "potential drainage density", exceto as dos PES e PEN. O DPD define-se pela medida entre a densidade do escoamento superficial e a capacidade de infiltração dos fluxos hídricos (DOBOS \& DAROUSSIN, 2007). O DPD é inversamente proporcional a capacidade de infiltração, isto é, a baixa permeabilidade e infiltração intensificam o escoamento superficial, aumentando seu poder erosivo e consequentemente o grau de dissecação de uma paisagem. Os domínios dos patamares, além de estarem profundamente dissecados nos quais as fraturas encontram-se alargadas, o padrão do escoamento superficial concentra-se nos vales ao passo que no restante do PNSC dispersa-se amplamente na chapada. 


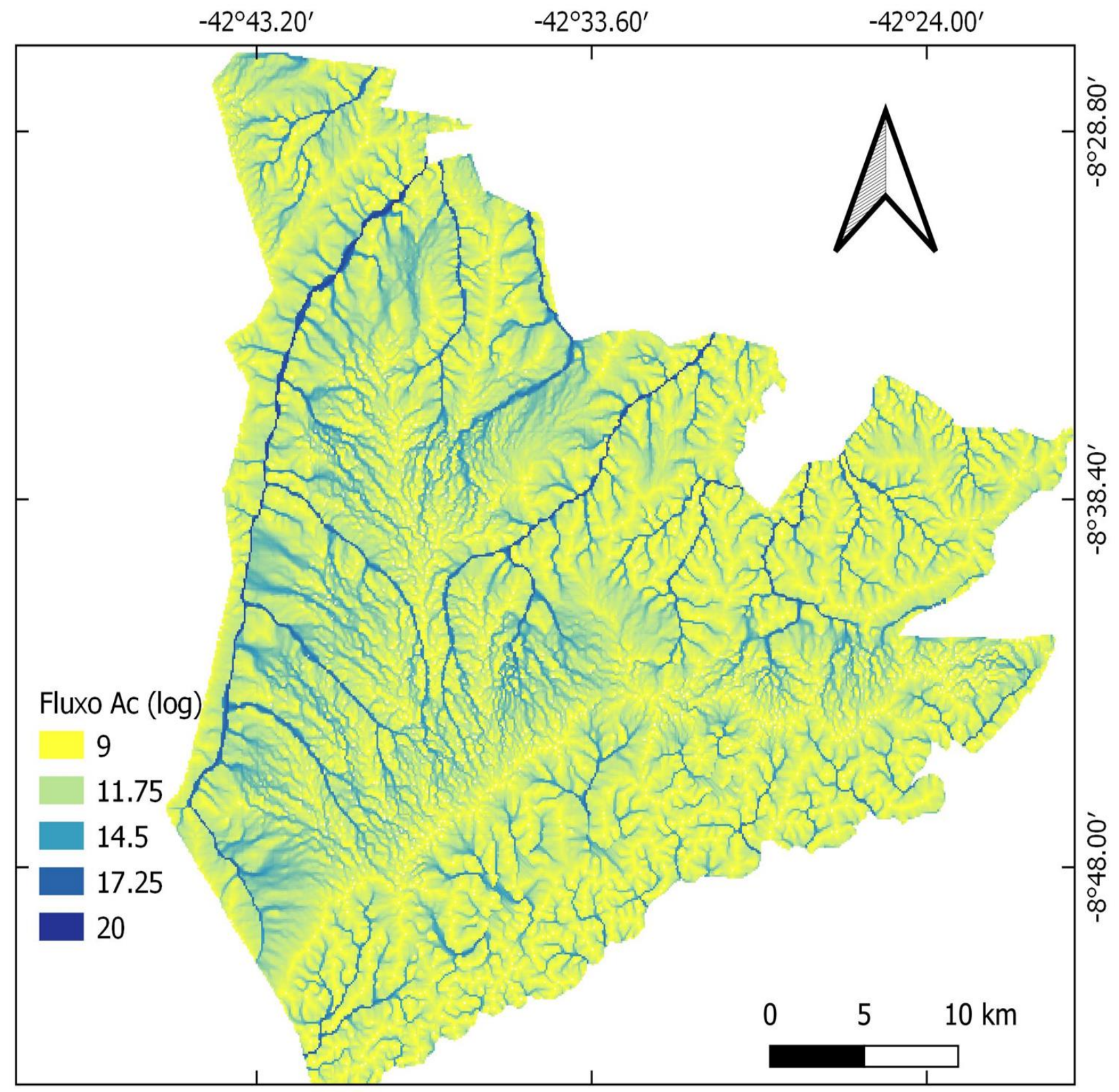

Figura 4. Mapa do fluxo acumulado modelado para a área do PNSC.

Ao menos quatro áreas com padrões de escoamentos direcionais distintos podem ser individualizadas pelos interflúvios que as delimitam (Figura 5). Cada zona de drenagem, identificadas neste trabalho, apresenta padrões de escoamento direcionais divergentes entre si, sendo esta outra característica que as permitem agrupá-las, além das unidades morfoestruturais subjacentes e a distribuição de elevação ao longo da zona de estudo.

Tais zonas de fluxo acumulado são influenciadas pelas unidades morfoestruturais identificadas e propostas por Santos et al. (2012). A zona de escoamento Sul é delimitada pelos PES que em contato com a unidade morfoestrutural formada pelo Reverso da Cuesta separa a zona de captação central homônima a última. A área de fluxo Norte é limitada das demais pelos paredões escarpados orientados N-S do Vale da Serra Branca. Por fim, a zona de escoamento que corresponde aos PEN tem como fronteira à leste o reverso da cuesta e a sul os PES. Esta última zona de drenagem apresenta maior área de abrangência de captação de fluxo do que os limites propostos por Santos et al. (2012). 


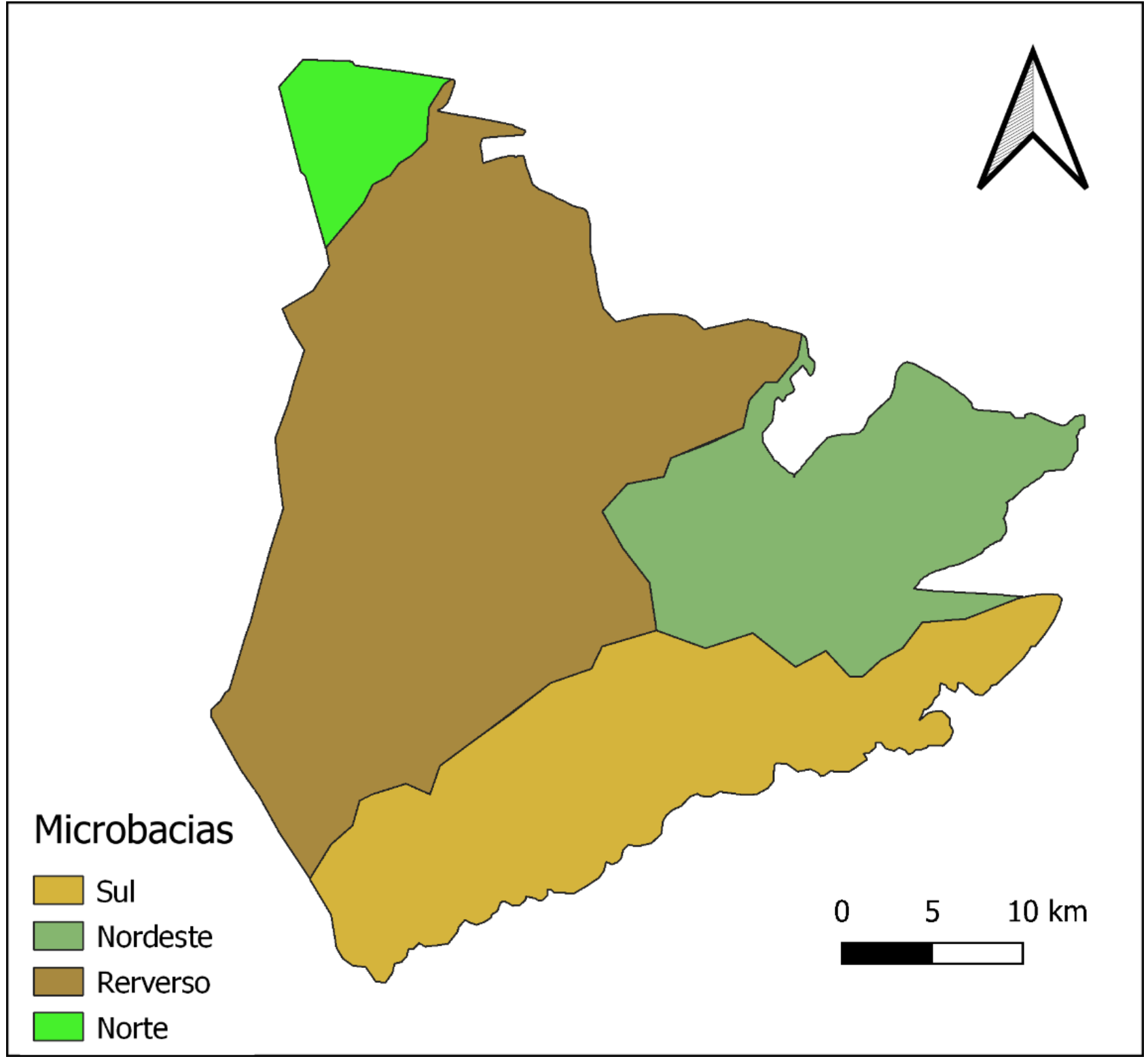

Figura 5. Interpretação das subdivisões das redes de drenagem no PNSC. Na imagem, as drenagens estão diferenciadas em função dos azimutes sendo a maior zona de drenagem a porção central correspondente ao reverso da cuesta.

O fator LS calculado para o PNSC foi divido em classes e pode ser visualizado na Figura 6 e na Tabela 1 que dispõe da área ocupada e a porcentagem correspondente. O valor médio do fator topográfico é de 7,1 com alto coeficiente de variação $(\mathrm{CV})$ de $17,9 \%$. O desvio dos valores LS representado pelo CV denota a distribuição da complexidade topográfica do terreno em termos de heterogeneidade do relevo (PANAGOS et al., 2015).

Os maiores valores do fator LS concentram-se em áreas de encostas íngremes associadas aos paredões dos vales que limitam as unidades morfoestruturais, assim como nas morfologias dissecadas desenvolvidas dentro dos PEN e dos PES, implicando que a declividade é o principal parâmetro controlador (DESMET \& GOVERS, 1996). As classes a partir de 20, são as mais expressivas no mapa, indicando as áreas com maior sensibilidade aos processos erosivos na região, concentrando-se nas áreas de relevo exumado dos patamares estruturais e do vale da Serra Branca. Correspondem a uma área de 26.266 hectares, aproximadamente 20,46\% da área mapeada, que recobre as regiões do Vale da Serra Branca a N-NW e as áreas NE e S-SE. Observa-se que dentro dos vales o fator LS limita-se a intervalos entre 20 e 50 devido ao grau de aplainamento do terreno. 


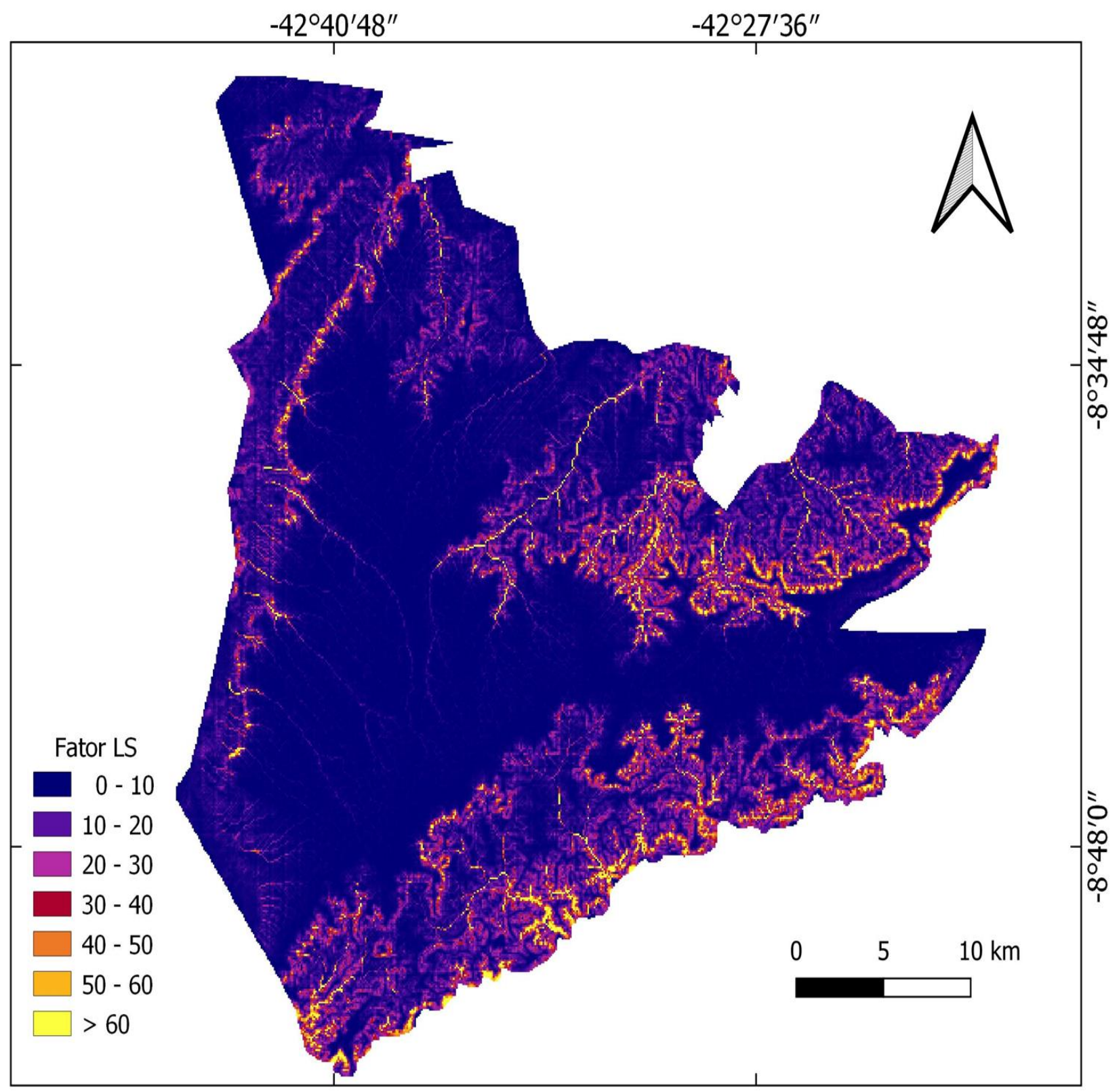

Figura 6. Mapa com intervalos de valores do Fator LS para a região do PNSC.

Tabela 1. Classes do fator LS por área no PNSC.

\begin{tabular}{ccc}
\hline CLASSE & ÁREA (hectares) & $\mathbf{\%}$ \\
\hline $0-10$ & 102.132 & 79,54 \\
\hline $10-20$ & 14.738 & 11,48 \\
\hline $20-30$ & 5.717 & 4,45 \\
\hline $30-40$ & 2.683 & 2,09 \\
\hline $40-50$ & 1.384 & 1,08 \\
\hline $50-60$ & 754 & 0,59 \\
\hline$>60$ & 990 & 0,77 \\
\hline TOTAL & 128.398 & 100.00 \\
\hline
\end{tabular}


Nos topos planos, apesar de contribuírem com maior área de contribuição de fluxo acumulado, os valores do fator LS apresentam-se entre 0 e 30, no geral. Deve-se este fato de os relevos de cimeira apresentarem maior dispersão da canalização dos fluidos e baixos gradientes. Além disso, a relação gradiente-comprimento, isto é, a extensão dos declives na qual se deriva o fator LS, é um elemento determinante para se computar a probabilidade dos efeitos erosivos (YITAYEW et al., 1999).

Nas áreas onde há grande convergência de fluxos, o fator LS não apresentou aumento significativo de seus valores, contrário ao observado por Zhang et al. (2013), os quais consideraram na simulação variações de limites de abrangência dos modelados de fluxo acumulado aumentados manualmente. As áreas de fundo dos vales nas quais predominam superfícies planas, apresentam, portanto, baixo potencial erosivo em relação aos declives adjacentes constituídos de escarpas íngremes, cujos gradientes elevados apresentam grande potencial de erosão remontante. Quando se considera o fluxo acumulado combinado ao fator LS, o potencial erosivo é relativamente maior nas áreas de relevo côncavo (ZHANG et al., 2013). As regiões N-NE (PEN), S-SE (PES), juntamente com as escarpas do Vale da Serra Branca concentram as áreas com os maiores valores adimensionais LS, onde predominam relevos ruiniformes residuais escarpados e sistemas de diaclases resultantes de reativação tardia ao Evento Brasiliano dos lineamentos do embasamento (BARBOSA \& FURRIER, 2012; LIMA \& JARDIM de SÁ, 2017). O complexo grau de dissecação nestas regiões, fruto da influência estrutural da borda da Bacia do Parnaíba (BARBOSA \& FURRIER, 2012), gera condições de desenvolvimento e aprofundamento dos vales.

Por ser uma variável baseada no gradiente topográfico, observa-se que o potencial erosivo através do fator LS, isoladamente, se associa preferencialmente às regiões de superfícies convexas de grande comprimento de rampa e elevado declive (VAN REMORTEL et al., 2004). Há de se ressaltar que outras variáveis como litologia e cobertura vegetal podem contribuir diretamente na condição erosiva de determinadas áreas, assim como a curvatura predominante das superfícies, no controle do escoamento superficial (MITASOVA \& MITAS, 2001). Ainda, a resolução da imagem SRTM utilizada no presente estudo pode extrapolar os valores encontrados do fator LS, sendo assim necessárias aplicações com imagens de maior resolução espacial a fim de obter uma maior acurácia (VAN REMORTEL et al., 2004) dos indicadores espaciais.

As áreas mais vulneráveis à erosão hídrica concentram mais de $90 \%$ dos sítios arqueológicos dentro dos limites atuais do PNSC. A distribuição desses sítios ocorre associada às escarpas erosivas em praticamente todo o PNSC. Na área sul, concentra-se a maioria destes sítios (PESSIS \& GUIDON, 2007), os quais estão dispostos ao longo dos cânions, nas áreas basais, onde ocorrem feições rochosas do tipo abrigo, assim como no front da cuesta que é recortado por formas ruiniformes com topos ovalados que perfazem padrões dendríticos de drenagem. Para fins de conservação, a identificação das áreas suscetíveis à erosão hídrica gera subsídios aos gestores do PNSC na tomada de decisões que contemplem a preservação do patrimônio arqueológico sujeito ao desgaste das intempéries naturais

Essa abordagem primária desenvolvida para a área de estudo é um passo inicial para fundamentar modelagens numéricas de terreno futuras para a região. Avanços posteriores deverão considerar o refinamento das técnicas, incorporando novas variáveis nos algoritmos, como, por exemplo, a relação entre as estimativas das curvaturas topográficas e sua influência na distribuição do fluxo acumulado, bem como a modelagem de escoamentos para estabelecer relações mais precisas com MDE de maior resolução.

\section{Conclusões}

Uma análise das áreas mais susceptíveis à erosão hídrica foi realizada no PNSC aplicando-se o fator adimensional LS derivado da EUPS, utilizando softwares SIG open-source. A construção do mapa do fator adimensional LS permitiu identificar e quantificar as áreas mais vulneráveis e de maior potencial de atuação dos processos erosivos por escoamento superficial. O mapeamento da rede de drenagem (fluxo acumulado) permitiu identificar a presença de quatro microrredes de drenagem influenciadas pela distribuição da elevação em função das unidades morfoestruturais desenvolvidas na região de estudo.

O gradiente de declividade e o seu comprimento são os principais parâmetros controladores da erosão hídrica no PNSC e que áreas com maior fluxo acumulado não apresentam valores significativamente maiores do fator LS. As áreas N-NE e S-SE são as mais vulneráveis à erosão. O grau e complexidade de dissecação no desenvolvimento de relevos ruiniformes produzem os maiores índices. 
Outras variáveis devem ser introduzidas no modelo de análise da vulnerabilidade à erosão na região do PNSC em pesquisas futuras no intuito de precisar a qualidade dos dados desenvolvidos no presente estudo. Escalas de mapeamento maiores deverão ser utilizadas para detalhar com maior precisão os processos erosivos associados ao relevo do contexto estudado.

Esse mapeamento básico serve de subsídio para iniciativas de avaliação e proteção da área que abriga achados arqueológicos pré-históricos e históricos importantes como, por exemplo, as pinturas rupestres preservadas nas encostas dos cânions.

Contribuições dos Autores: Concepção, R. J. A. Macêdo; metodologia, R. J. A. Macêdo; software, R. J. A. Macêdo; pesquisa, R. J. A. Macêdo; preparação de dados, R. J. A. Macêdo; escrita do artigo, R. J. A. Macêdo, J. C. Santos e L. Surya; revisão, R. J. A. Macêdo, J. C. Santos e L. Surya. Todos os autores leram e concordaram com a versão publicada do manuscrito.

Financiamento: Esta pesquisa não recebeu nenhum financiamento externo.

Agradecimentos: Os autores agradecem à UNIVASF pela bolsa PIBIC concedida para o projeto "Mapeamento da vulnerabilidade à erosão no Parque Nacional Serra da Capivara" que culminou neste artigo. Agradecemos ainda a contribuição dada pelos revisores através das críticas construtivas que colaboraram para o aperfeiçoamento do manuscrito.

Conflito de Interesse: Os autores declaram não haver conflito de interesse.

\section{Referências}

1. ALMEIDA, F.F.M, HASUI, Y, BRITO NEVES, B.B, FUCK, R.A. Províncias Estruturais Brasileiras. In: VIII Simpósio de Geologia do Nordeste, Atas, 363-391, 1977.

2. BRITO NEVES, B. B. Regionalização Geotectônica do Pré-Cambriano Nordestino. 198 f. Tese (Doutorado em Geologia). Universidade de São Paulo, São Paulo, 1975.

3. BRITO NEVES, B. B.; SANTOS, E. J.; VAN SCHMUS, W. R. Tectonic history of the Borborema Province, northeastern Brazil. In: U. G. CORDANI, E. J. MILANI, A. THOMAZ FILHO \& D. A. CAMPOS (Eds.): Tectonic evolution of South America, 2001. $854 \mathrm{p}$.

4. BARBOSA, M. E. F \& FURRIER, M. Sistemas de diaclases e influência tectônica da borda sudeste da bacia sedimentar do Parnaíba: Parque Nacional Serra da capivara, Brasil. Revista do Departamento de geografia, 23: 250-266, 2012. DOI: https://doi.org/10.7154/RDG.2012.0023.0011

5. BARROS, J. S.; FERREIRA, R. V.; PEDREIRA, A. J.; GUIDON, N. (2012). Geoparque Serra da Capivara: proposta. In: SCHOBBENHAUS, C.; SILVA, C. R. (Org.). Geoparques do Brasil: propostas. Rio de Janeiro: CPRM, 2011. Cap. 14. Disponível em: <http://rigeo.cprm.gov.br/jspui/handle/doc/14608>

6. BEZERRA, S. A. \& CANTALICE, J. R. B. Erosão entre sulcos em diferentes condições de cobertura do solo, sob cultivo da cana-de-açúcar. R. Bras. Ci. Solo, 30: 565-573, 2006. DOI: https://doi.org/10.1590/S0100-06832006000300016.

7. BOGGS, S. Jr. Principles of Sedimentology and Stratigraphy. 4th ed. Pearson Education, Inc. 2006. 662p.

8. BORGES, K. M. R. Avaliação da susceptibilidade erosiva da Bacia do Rio Carinhanha (MG/BA) por meio da EUPS Equação Universal de Perda de Solos. Dissertação (Mestrado em Geografia). Departamento de Geografia. Universidade de Brasília. 2009. $91 \mathrm{p}$.

9. CAXITO, F. A. \& UHLEIN, A. Arcabouço Tectônico e Estratigráfico da Faixa Riacho do Pontal, Divisa Pernambuco-PiauíBahia. Geonomos, 21(2): 19-37, 2013.

10. CAPOLONGO, D.; PENNETTA, M.; FALLACARA, G.; BOENZI, F. Spatial and temporal variations in soil erosion and deposition due to land-levelling in a semi-arid area of Basilicata (Southern Italy). Earth Surf. Process. Landforms, 33: 364-379, 2008. DOI: https://doi.org/10.1002/esp.1560

11. CAPUTO, M. V. Late Devonian glaciation in South America. Palaeogeography, Palaeclimatology, Palaeoecology, 51: 291317, 1985. DOI: https://doi.org/10.1016/0031-0182(85)90090-2

12. CAPUTO, M. V.; IANNUZZI, R.; FONSECA, V. M. M. 2005. Bacias sedimentares brasileiras: Bacia Sedimentar do Parnaíba. Phoenix, 7(81): 1-7.

13. CASTELLETTI, C. H. M.; SILVA, J. M. C.; TABARELLI, M.; SANTOS, A. M. M. 2003. Quanto ainda resta da Caatinga? Uma estimativa preliminar. Disponível em: <https://ainfo.cnptia.embrapa.br/digital/bitstream/item/18266/1/Caatinga.pdf>

14. DESMET, P. J. J. \& GOVERS, G. A GIS procedure for automatically calculating the USLE LS factor on topographically complex landscape units. J. Soil and Water Cons., 51(5): 427-433, 1996. 
15. DOBOS, E. \& DAROUSSIN, J. Calculation of Potential Drainage Density Index (PDD). In: PECKHAM, R. J. \& JORDAN, G. (Eds.). Digital Terrain Modelling: Development and Applications in a Policy Support Environment. Springer-Verlag Berlin Heidelberg, 2007, p. 283-295.

16. FLORENZANO, T. G (Org.). Geomorfologia: conceitos e tecnologias atuais. São Paulo: Oficina de Textos, 2008.318 p.

17. FUMDHAM. Parque Nacional Serra da Capivara. Alínea publicações editora (Teresina/PI), 1998. 94 p.

18. GUERRA, A. J. T. \& CUNHA, S. B. Geomorfologia: uma atualização de bases e conceitos. $7^{a}$ ed. Rio de Janeiro: Bertrand Brasil, 2007. 472p.

19. GURGEL, R. S.; CARVALHO JÚNIOR, O. A.; GOMES, R. A. T.; GUIMARÃES, R. F.; CÂMARA, J. F. A.; SOBRINHO, D. A.; MARTINS, E. S.; BRAGA, A. R. S. Identificação das áreas vulneráveis à erosão a partir do emprego da EUPS - equação universal de perdas de solos no município de Riachão das Neves - BA. Geografia Ensino \& Pesquisa, v.15, n.3, set/dez (2011). DOI: http://dx.doi.org/10.5902/223649947348

20. HENGL, T \& REUTER, H. I. (Eds.). Geomorphometry: Concepts, Software, Applications. 1st ed. Volume 33. Elsevier, 2009. $796 \mathrm{p}$.

21. HUGGET, R. J. Fundamentals of Geomorphology. 2 ed. Madison: Routledge, New York, 2007. 458 p.

22. JÚNIOR, F. R. A. \& NOGUEIRA, A. C. R. Reconstituição paleoambiental das formações Motuca e Sambaíba, PermoTriássico da Bacia do Parnaíba no sudoeste do Estado do Maranhão, Brasil. Geol. USP, Sér. cient., 13(3): 65-82, 2013. DOI: http://dx.doi.org/10.5327/Z1519-874X201300030007

23. LIMA, F. G. F. \& JARDIM DE SÁ, E. F. Controle estrutural da borda sudeste da Bacia do Parnaíba, Nordeste do Brasil: relação com eventos geodinâmicos no Gondwana. Geol. USP, Sér. cient., 17(3): 3-21, 2017. DOI: 10.11606/issn.2316-9095.v17125909

24. MABESOONE, J. M. História Geológica da Provícia Borborema (NE Brasil). Revista de Geologia, 15: 119-129, 2002.

25. METCALFE, P.; BEVEN, K.; FREER, J. TOPMODEL: A new implementation in R and its sensitivity to time and space steps. Envinronmental Modelling and Software, 72: 155-172, 2015. DOI: https://doi.org/10.1016/j.envsoft.2015.06.010

26. MITASOVA, H.; HOFIERKA, J.; ZLOCHA, M.; IVERSON, L. R. Modelling topographic potential for erosion and deposition using GIS. Int. J. Geographical Information Systems, 10(5):629-641, 1996. DOI: https://doi.org/10.1080/02693799608902101

27. MITASOVA, H. \& MITAS, L. Multiscale Soil Erosion Simulations for Land Use Management. In: Harmon R.S., Doe W.W. (eds) Landscape Erosion and Evolution Modeling. Springer, Boston, MA. 2001, 41-68. https://doi.org/10.1007/978-1-4615-05754_11

28. MITASOVA, H.; THAXTON, C.; HOFIERKA, J.; McLAUGHLIN, R.; MOORE, A.; MITAS, L. Path sampling method for modeling overland water flow, sediment transport, and short-term terrain evolution in Open Source GIS. Developments in Water Science, 55, 1479-1490, 2004. DOI: https://doi.org/10.1016/S0167-5648(04)80159-X

29. MUTZENBERG, D. S.; CORREA, A. C. B.; TAVARES, B. A. C.; CISNEIROS, D. Serra Da Capivara National Park: Ruinform Landscapes on The Parnaiba Cuesta. In: VIEIRA, B. C.; SALGADO, A. A. R.; SANTOS, L. J. C. (org.). Landscapes and Landforms of Brazil. Springer Netherland, 2015. p. 243-263.

30. NETEleR, M. \& MITASOVA, H. Open Source GIS: A GRASS GIS approach. Second edition. Kluwer Academic Publishers. 2004. 406 p.

31. NETO, M. V. B.; ARAÚJO, M. S. B.; FILHO, J. C. A.; ALMEIDA, B. G. Degradação do solo por erosão em área vulnerável à desertificação no semiárido pernambucano. XVII Simpósio Brasileiro de Geografia Física Aplicada, 4406-4416, 2017.

32. PANAGOS, P.; BORRELLI, P.; MEUSBURGER, K. A new European slope length and steepness factor (LS-Factor) for modeling soil erosion by water. Geosciences, 5: 117-126, 2015. DOI: 10.3390/geosciences5020117

33. PESSIS, A. M. \& GUIDON, N. Serra da Capivara National Park, Brazil: cultural heritage and society. The Archeology of World Heritage, 39(3): 406-416, 2007. DOI: https://doi.org/10.1080/00438240701504676

34. QGIS development team. 2019. QGIS Geographic Information System (versão 3.0). Disponível em: <http://qgis.org/> 35. RAPP, A. Introduction to soil degradation processes in drylands. Climatic Changes, 9(1): 19-31, 1986. DOI: https://doi.org/10.1007/BF00140521

36. SANTOS, D. N.; SILVA, V. P. R.; SOUSA, F. A. S.; SILVA, R. A. Estudo de alguns cenários climáticos para o Nordeste do Brasil. Rev. Bras. Eng. Agríc. Ambient., 14(5): 492-500, 2010. DOI: https://doi.org/10.1590/S1415-43662010000500006

37. SANTOS, J. C.; BARRETO, A. M. F. \& SUGUIO, S. Quaternary deposits in the Serra da Capivara National Park and surrounding area, Southeastern Piaui state, Brazil. Geol. USP, Sér. cient., 12(3): 115-132, 2012. DOI: 10.5327/Z1519$874 \times 2012000300008$ 
38. SANTOS, L. J. C.; OKA-FIORI, C.; CANALLI, N. L.; FIORI, A. P.; SILVERIA, C. T.; SILVA, J. M. F. Mapeamento da vulnerabilidade geoambiental do estado do Paraná. Revista Brasileira de Geociências, 37(4): 812-820, 2007. DOI: 10.25249/03757536.2007374812820

39. SHI, Z. H.; CAI, C. F.; DING, S. W.; WANG, T. W.; CHOW, T. L. Soil conservation planning at the small watershed level using RUSLE with GIS: a case of study in the Three Gorge Area of China. Catena, 55: 33-88, 2004. DOI: https://doi.org/10.1016/S0341-8162(03)00088-2

40. SILVA, R. M.; PAIVA, F. M. L.; SANTOS, C. A. G. Análise do grau de erodibilidade e perdas do solo na bacia do rio Capiá baseado em SIG e sensoriamento remoto. Revista Brasileira de Geografia Física, 2(1): 26-40, 2009. DOI: https://doi.org/10.26848/rbgf.v2.1.p26-40

41. SILVA, P. C. G.; MOURA, M. S. B.; KIILL, L. H. P.; BRITO, L. T. L.; PEREIRA, L. A.; SA, I. B.; CORREIA, R. C.; TEIXEIRA, H. H. C.; CUNHA, T. J. F.; GUIMARÃES FILHO, C. (2010). Caracterização do Semiárido brasileiro: fatores naturais e humanos. In: SA, I. B.; SILVA, P. C. G. da. (Ed.). Semiárido brasileiro: pesquisa, desenvolvimento e inovação. Petrolina: Embrapa Semiárido. Embrapa Semiárido-Capítulo em livro científico (ALICE), 1, p. 18-48. Disponível em: <https://www.alice.cnptia.embrapa.br/handle/doc/861906>

42. SILVA, V. P. R; PEREIRA, E. R. R.; AZEVEDO, P. V.; SOUSA, F. A. S.; SOUSA, I. F. Análise da pluviometria e dias chuvosos na região Nordeste do Brasil. Rev. Bras. Eng. Agríc. Ambiental, 15(2): 131-138, 2011. DOI: https://doi.org/10.1590/S141543662011000200004

43. VAN REMORTEL, R. D.; MAICHLE, R. W.; HICKEY, R. J. 2004. Computing the LS factor for the Revised Universal Soil Loss Equation through array-based slope processing of digital elevation data using a C++ executable. Computers \& Geosciences, 30: 1043-1053. DOI: 10.1016/j.cageo.2004.08.001

44. WILlGOOSE, G. 2018. Principles of Soilscape and Landscape Evolution. Cambridge University Press. 337 p. DOI: $10.1017 / 9781139029339$

45. WISCHMEIER, W. H. \& SMITH, D. D. 1978. Predicting rainfall erosion losses: a guide to conservation planning Washington: USDA/ARS. Disponível em: <https://naldc.nal.usda.gov/download/CAT79706928/PDF>

46. YITAYEW, M.; POKRZYWKA, S. J.; RENARD, K. G. 1999. Using GIS for facilitating erosion estimation. Applied Engineering in Agriculture, 15(4): 295-301.

47. ZHANG, H.; YANG, Q.; LI, R.; LIU, Q.; MOORE, D.; HE, P.; RITSEMA, C. J.; GEISSEN, V. Extension of a GIS procedure for calculating the RUSLE equation LS factor. Computers \& Geoscience, 52: 177-188, 2013. DOI: 10.1016/j.cageo.2012.09.027

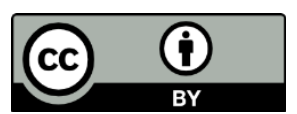

Esta obra está licenciada com uma Licença Creative Commons Atribuição 4.0 Internacional (http://creativecommons.org/licenses/by/4.0/) - CC BY. Esta licença permite que outros distribuam, remixem, adaptem e criem a partir do seu trabalho, mesmo para fins comerciais, desde que lhe atribuam o devido crédito pela criação original. 